\title{
The Canvas LMS Systems' Advanced Possibilities in Course Design and the Usage of Evaluation in Formal, Non-formal and Informal Education
}

\author{
ABONYI-TÓTH Andor
}

\begin{abstract}
From the 2016's academic year, the Eötvös Loránd University, in addition to the Moodle framework, also enabled teachers to use the OpenSource version of the Canvas LMS, not only for courses related to formal education but for course-based or even open courses (MOOC). An essential aspect of choosing the framework was to have built-in features which support advanced approaches to the course management and evaluation (e.g., teamwork, peer review, advanced module organization, student differentiation, collaborative opportunities, outcome-based education, rubrics). In my article, besides presenting the usage of the mentioned functions in education, I also summarize the statistics of the usage of this system as well as the teacher's feedback.
\end{abstract}

Keywords: Canvas LMS, differentiation, learning management, grading schemes.

\section{Introduction}

ELTE is Hungary's most prestigious university with the richest traditions and the highest international rankings in the country, where tradition and innovation go hand-in-hand ${ }^{1}$. The field of e-learning also has an important role in our institution, we support our courses with different learning management systems (LMS). From the 2016/17's academic year (besides the previously started Moodle system) we provide the usage of the Canvas system to our instructors and students.

With the introduction of the Canvas system, we intended to support not only just formal but also the informal education as well. Because of technical reasons we choose to run two versions of Canvas, the first one (canvas.elte.hu) is to support the formal education, while the second one (mooc.elte.hu) had been created for open courses, further teacher training, etc.

The interaction with the Neptun Education system which is used in the Hungarian higher educational institutions was solved in January 2017, allowing the instructors to initiate the creation of e-learning courses from the education system. Instructors and students are automatically given access to the courses that have been created, they can enter into the system with the Neptun ID which they are already familiar with. In the Canvas system that is used in formal education, statistics are available for each semester (see Table 1.)

\begin{tabular}{|c|c|c|c|}
\hline Semester & Number of courses & $\begin{array}{c}\text { Number of } \\
\text { instructors }\end{array}$ & $\begin{array}{c}\text { Number of } \\
\text { students }\end{array}$ \\
\hline $2016 / 17 / 2$ & 212 & 104 & 3686 \\
\hline $2017 / 18 / 1$ & 276 & 124 & 4642 \\
\hline $2017 / 18 / 2$ & 301 & 168 & 5106 \\
\hline $2018 / 19 / 1$ & 463 & 281 & 8449 \\
\hline $2018 / 19 / 2$ & 606 & 375 & 9766 \\
\hline
\end{tabular}

Table 1: Statistical data on the Canvas environment for formal education

\footnotetext{
${ }^{1}$ ELTE Brochure: https://www.elte.hu/file/ELTEkiadvany2015.pdf
}

Central-European Journal of New Technologies in Research, Education and Practice 
The popularity of the Canvas framework is visibly constantly increasing, and now colleagues are launching three times more courses than three years ago. Table 2 shows how they started courses are distributing between the Canvas and Moodle systems.

\begin{tabular}{|c|c|c|c|}
\hline Semester & $\begin{array}{c}\text { Number of all } \\
\text { the courses }\end{array}$ & $\begin{array}{c}\text { Number of Canvas } \\
\text { courses }\end{array}$ & $\begin{array}{c}\text { Number of Moodle } \\
\text { courses }\end{array}$ \\
\hline $2016 / 17 / 2$ & 1171 & $212(18 \%)$ & $959(82 \%)$ \\
\hline $2017 / 18 / 1$ & 1338 & $276(21 \%)$ & $1062(79 \%)$ \\
\hline $2017 / 18 / 2$ & 1287 & $301(23 \%)$ & $986(77 \%)$ \\
\hline $2018 / 19 / 1$ & 1840 & $463(25 \%)$ & $1377(75 \%)$ \\
\hline $2018 / 19 / 2$ & 1880 & $606(32 \%)$ & $1274(68 \%)$ \\
\hline
\end{tabular}

Table 2: Distribution of all formal courses between the two frameworks

One of the reasons for Moodle's popularity that it was introduced at our university before Canvas, so most of the instructors were reluctant for switching to a new framework. Besides this, there is also a group of instructors who are keen to experiment with the functions of this new framework and use its advanced course management and evaluation capabilities. It is clearly visible that almost one-third of the courses are launching in the Canvas system, and that more and more instructors are setting up e-learning courses to support learning.

In a Canvas copy which supports informal and non-formal courses, instructors can request the creation of courses by filling in a form, after the verification of the data, the course is created manually. In this framework, a total of 2169 courses have been announced ${ }^{2}$, most of which are such test courses in which instructors can test the capabilities of the system during the course, and experiment with certain functions. We have 510 courses in which there is real training, which means that students are also enrolled in.

For this system, we did not examine the number of courses in a breakdown by semester, because here the start and end dates of the courses can be set arbitrarily, so short (a few weeks) or longterm (multiple semesters long) courses can be started.

\section{Possibilities for organizing and evaluating the Canvas course}

In the Canvas framework, the first page of the course - which appears at first after entering the course - can be varied based on the choice of the instructor: the syllabus, the front page edited by the instructor, the assignments list, the course activity stream, and the modules list [1].

In the 2016/17/2 semester, we examined what instructors prefer to set as their home page. As a result, we got to know that most of the instructors chose the course activity stream as their home page $(52 \%)$, followed by the modules $(27 \%)$, the syllabus $(13 \%)$, the content page $(8 \%)$, and finally the assignments list (1\%) setting [2].

\footnotetext{
2 According to the March 31, 2019 status
}

Central-European Journal of New Technologies in Research, Education and Practice

Volume 2, Number 1, 2020. 


\subsection{Module Organizational options, experiences}

In the Canvas framework, modules allow to group content according to a specific aspect, whether it is a variety of different topics or even teaching weeks. For each module, precondition can be set, as well as the conditions required for the module to be considered complete. The conditions may not only include hand-ins to be submitted, but also that students need to intervene in editing the page or writing a forum post. These options allow a wide range of course management solutions.

Among the published courses in the examined semester, 74 were found $(35 \%)$ where the instructors created forums, while the number of comments was low, only $8 \%$ of the courses included more than hundreds of forum posts [2].

The way students have completed each module can also be easily queried with the "Module Progress" function. Here we can see which modules have been completed and which elements are still to be completed.

In the case of smaller courses with fewer thematic units, it is not necessary to design the modules, the topic itself or the syllabus can illustrate the structure and requirements of the course. But over a certain complexity, module management becomes essential. Regarding the 212 launched courses in the examined semester, we can state that there were no modules in just over half of the courses.

\subsection{Consultation, organization of the exam work presentation}

In blended education, it is common for students to access the curricula and exercises online, but they must defend their examinations personally at a given time. Even in the case of online courses, which only take place on the electronic interface, it may be important for students to be able to consult online with the instructors in a particular interval. In this case, the most ideal would be if students could register for the appointments offered by the instructor. This feature is supported default on the Canvas LMS by selecting the scheduler in the calendar, after which students can specify the characteristics of each consultation time.

\subsection{Supporting teamwork and collaboration}

Canvas's framework supports the set of groups at different levels. The so-called „Sections” should be used in case if we present a course parallel (or shifted in time) for multiple groups, and we want to differentiate the individual groups according to that the same tasks have different end lines. In the case of these sections, we can set that students are allowed to communicate with students from different sections, with their own groupmates or with everybody.

We can also set up groups when we are setting the tasks. The set of groups created to implement a particular project is called group set. When we create a group setting, we can declare whether we to allow self-organizing groups to be created, or that, students can apply themselves to a particular group.

We can also set whether group members should be in the same section or not. Canvas also creates a group work interface for each group, where students can collaborate virtually with each other (editing pages, creating forums, collectively editable documents, current announcements, etc.) so they do not necessarily have to meet in person.

Central-European Journal of New Technologies in Research, Education and Practice

Volume 2, Number 1, 2020. 
Groups can be created randomly after we have specified the number of groups, but we can arrange students either manually, by using the drag and drop technique. In the groups, we can also manually select a group leader, but this can also happen automatically, which is going to be either the first joined student or chosen by the random selection. The group leader allowed to change the name of the group, which can be useful when the members themselves decide which project to implement.

When we are setting the tasks, we can also declare the task to be done in group work. We can either assign the task to an existing group set or assign it to the students individually.

During group work, it is essential that students can communicate with each other and work together. For this, the Canvas framework provides forums, internal correspondence, and shared real-time document management by integrating the Google Docs or EtherPad service.

\subsection{Advanced evaluation options}

To evaluate the tasks, the framework provides many convenient features. One of these is the „Speedgrader", which shows the uploaded files sorted by the students (in many cases these are viewable online), and on the interface, it is possible to add scores, evaluations, comments instantly, even based on rubrics, which we are going to discuss later on in more details. We can export the scores or import them from an external source into the framework.

The different types of tasks (e.g., teamwork, individual work, attendance, smaller classroom tests, hand-ins, micro-presentations) can be organized into so-called task-groups, and the achieved scores can be weighted (Figure 1.) according to these groups [1].

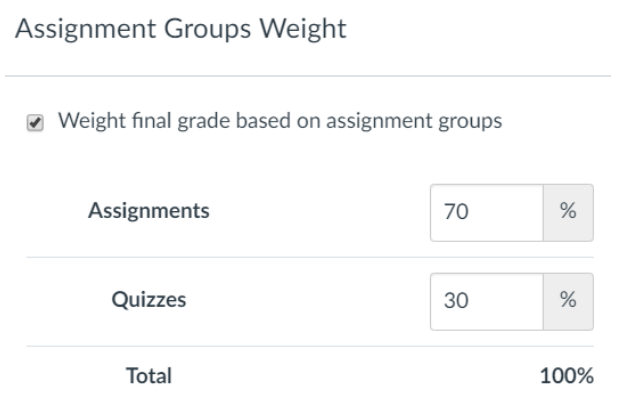

Figure 1: Setting assignment groups weight

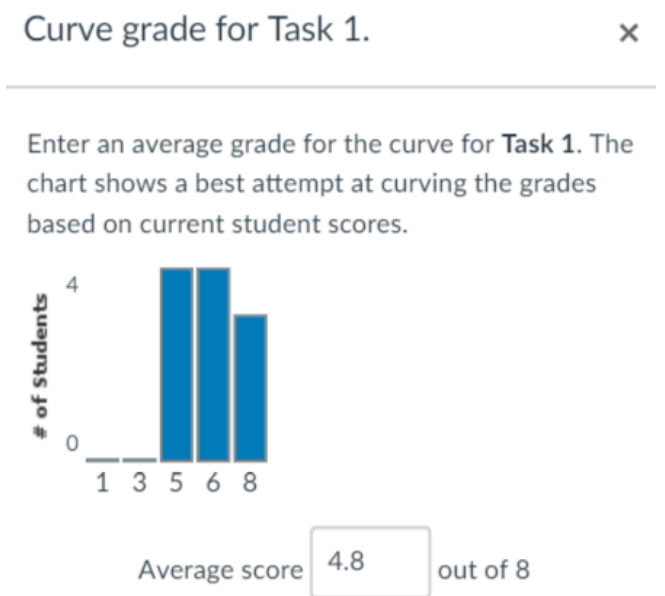

$\square$ Assign zeroes to unsubmitted students

Figure 2: Curving grades for an assignment

In the case of published assignments, quizzes, surveys, it is worth noting that we can order extra chances and time for students. This option is suitable for remedying possible technical errors (e.g., computer crashes) just like enforcing the rights of disabled students (e.g., extra preparation time). 
Due to the nature of the tasks, we can apply criteria-oriented or norm-oriented assessment [3]. In the last case, the performance of the students can be compared to each other or to the achieved average by a reference group. Throughout this, we can determine that the student's performance is in which performance area. Therefore, in such evaluations, it would be important to compare student's performance to the achieved average by the group (or reference group). This function of the Canvas LMS (Figure 2) is suitable for this to correct the scores achieved by students.

The system allows the evaluation of tasks in the form of peer reviews. Several advantages are known for using peer reviews [4]:

- Peer review builds student investment in writing and helps students understand the relationship between their writing and their coursework in ways that undergraduates sometimes overlook.

- Making the writing process more collaborative through peer review gives students opportunities to learn from one another and to think carefully about the role of writing in the course at hand.

- Studies have shown that even strong writers benefit from the process of peer review: students report that they learn as much or more from identifying and articulating weaknesses in a peer's paper as from incorporating peers' feedback into their own work.

- Peer review provides students with contemporary models of disciplinary writing.

- Peer review allows students to clarify their own ideas as they explain them to classmates and as they formulate questions about their classmates' writing.

- Peer review provides a professional experience for students having their writing reviewed.

- Peer review minimizes last-minute drafting and may cut down on common lower-level writing errors.

Peer reviews can be set during the process of setting the individual tasks, after that, we can set manually that who evaluate whose work (even in an anonymous way) or we let the system to assign the tasks.

In order for the evaluation to take place from a specific angle, we can also associate the tasks with a so-called rubric (Figure 3), which helps to allocate the partial points easily. In the absence of this, the evaluation of the tasks will be highly subjective and unfair, because it greatly depends on the evaluator's own aspects, and students will not know the reason why they lost points.

\begin{tabular}{|c|c|c|c|c|c|c|c|c|}
\hline \multicolumn{8}{|l|}{ Blog writing } & \multirow{2}{*}{$\begin{array}{l}\text { Q } Q \bar{\amalg} \\
\text { Pts }\end{array}$} \\
\hline Criteria & \multicolumn{7}{|c|}{ Ratings } & \\
\hline $\begin{array}{l}\text { Quality of } \\
\text { Writing }\end{array}$ & $\begin{array}{l}4.0 \text { pts } \\
\text { Expert } \\
\text { very informative or } \\
\text { deeply reflective; } \\
\text { informational post: } \\
\text { synthesizes learned } \\
\text { content and } \\
\text { constructs new } \\
\text { meaning; well } \\
\text { organized }\end{array}$ & \multicolumn{2}{|c|}{$\begin{array}{l}3.0 \text { pts } \\
\text { Accomplished } \\
\text { some new } \\
\text { information on the } \\
\text { topic or reflective; } \\
\text { informational post: } \\
\text { attempts to } \\
\text { synthesize } \\
\text { information and form } \\
\text { new meaning; well } \\
\text { organized }\end{array}$} & \multicolumn{2}{|c|}{$\begin{array}{l}2.0 \text { pts } \\
\text { Capable } \\
\text { gives some new information } \\
\text { on the topic; informational } \\
\text { post: has trouble with } \\
\text { integrating read or learned } \\
\text { information and mostly } \\
\text { repeats without construction } \\
\text { of new meaning; poorly } \\
\text { organized }\end{array}$} & $\begin{array}{l}1.0 \text { pts } \\
\text { Beginner } \\
\text { gives no new information } \\
\text { on the topic; } \\
\text { nformational post: there } \\
\text { is little to no evidence of } \\
\text { other readings or } \\
\text { information in order to } \\
\text { form new meaning; } \\
\text { poorly organized }\end{array}$ & $\begin{array}{l}0.0 \mathrm{pts} \\
\text { No } \\
\text { Marks }\end{array}$ & $4.0 \mathrm{pts}$ \\
\hline Presentation & \multicolumn{2}{|c|}{$\begin{array}{l}4.0 \text { pts } \\
\text { Expert } \\
\text { all words spelled correctly; } \\
\text { no grammar errors } \\
\text { formatting makes the post } \\
\text { more interesting and } \\
\text { easier to read }\end{array}$} & \multicolumn{2}{|c|}{$\begin{array}{l}3.0 \text { pts } \\
\text { Accomplished } \\
\text { few spelling errors; few } \\
\text { grammar errors; some } \\
\text { formating to help } \\
\text { make the post easier to } \\
\text { read }\end{array}$} & $\begin{array}{l}2.0 \mathrm{pts} \\
\text { Capable } \\
\text { several spelling errors; } \\
\text { several grammar } \\
\text { errors; formatting } \\
\text { makes post difficult to } \\
\text { follow or read }\end{array}$ & $\begin{array}{l}1.0 \text { pts } \\
\text { Beginner } \\
\text { many words } \\
\text { misspelled; many } \\
\text { grammar errors; } \\
\text { formatting makes post } \\
\text { difficult to follow or } \\
\text { read }\end{array}$ & $\begin{array}{l}0.0 \mathrm{pts} \\
\text { No } \\
\text { Marks }\end{array}$ & $4.0 \mathrm{pts}$ \\
\hline
\end{tabular}

Figure 3: An example Rubric about the blog writing

Central-European Journal of New Technologies in Research, Education and Practice

Volume 2, Number 1, 2020. 
Therefore, to determine grades based on student results, we need to create a so-called course grading scheme in which we specify the intervals for each grade according to the percentage of the results they achieved. We can set the grading schemes at the system level, so the instructors only have to choose from the predefined schemas and they only need to create new ones if they want to grade based on their own schema.

Besides the determination of the grades, students' learning outcomes can be specified in more detail (or it is maybe even recommended to do so), to achieve this in the Canvas framework there is a menu called „Learning outcomes” [1]. Learning outcomes are ,statements that describe the knowledge or skills students should acquire by the end of a particular assignment, class, course, or program, and help students understand why that knowledge and those skills will be useful to them"3.

In the Canvas LMS system, learning outcomes can be included among the criteria of the rubrics for the test forms used in the course, and scores can be assigned to each level of skills [5].

\subsection{Statistics, analytics}

The instructor's work is supported by built-in statistical and analytical modules. In the statistics which are available for quizzes and surveys, there are different metrics (achieved minimum, maximum, standard deviation, average score, average fill time) available, and we can see the results even sorted by questions, where in addition to the achieved results the discrimination index (D) is available too (Figure 4).

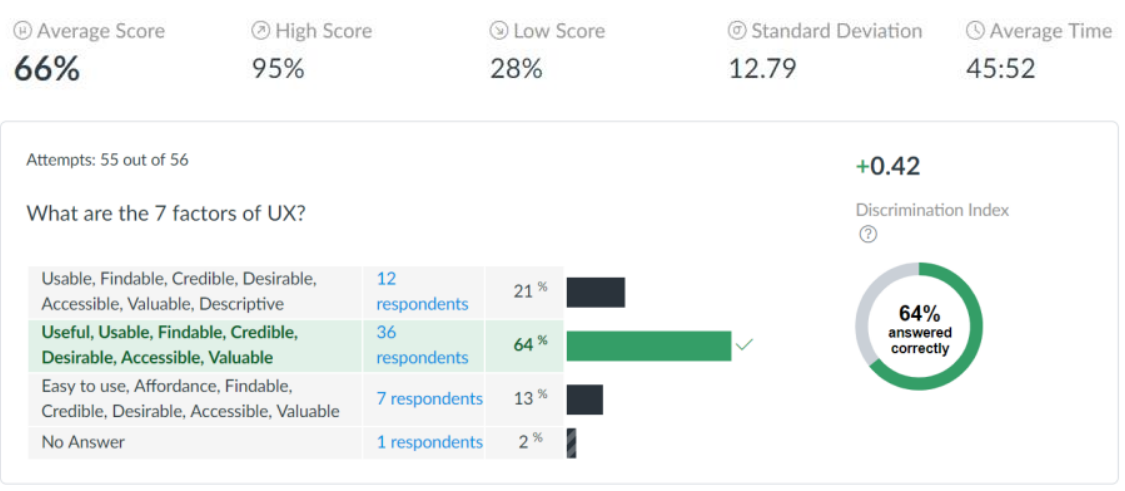

Figure 4: Results including the Discrimination Index

The item discrimination index is a „measure of how well an item is able to distinguish between examinees who are knowledgeable and those who are not, or between masters and non-masters 4 ". For the quizzes to differentiate appropriately between students, take a look at the achieved result, so we can improve the surveys based on those results. Questions with an index lower than 0.20 are worth reviewing, and the ones with the value of negative $\mathrm{D}$ are suggested to be deleted, or maybe it is advisable to check the key that there is no error in it.

\footnotetext{
${ }^{3}$ What Are Learning Outcomes? - Centre for Teaching Support \& Innovation. University of Toronto https://bit.ly/2IPU5fU

${ }^{4}$ Professional Testing, Inc | Test Topics. http://www.proftesting.com/test topics/steps 9.php
}

Central-European Journal of New Technologies in Research, Education and Practice

Volume 2, Number 1, 2020. 
Statistics are available for the entire course, including several levels. In a base level, we can see the number of forums/forum posts, tasks, uploaded hand-ins, quizzes, the number of students, we can query the names of the most recently enrolled students, as well as the information about the usage of the storage. More sophisticated statistics are provided by the so-called „analytics module” (Figure 5). Here we can see how page views and other activities have evolved over the past period, and we can track the status of each submissions status (on time/late/missing tasks).

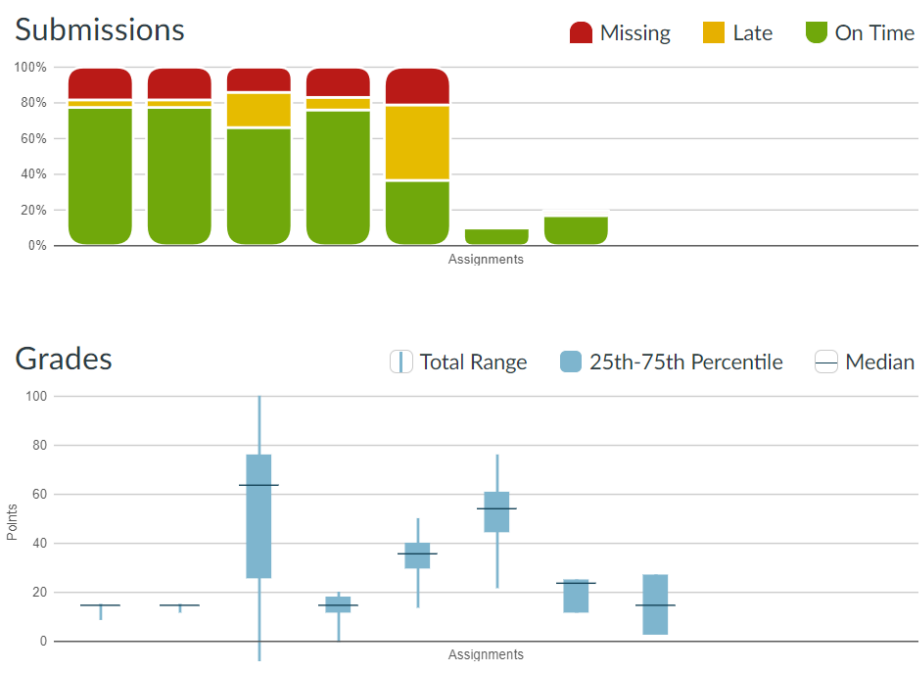

Figure 5: Course Analytics

For the tasks that have already been submitted and evaluated, a Box-Whisker diagram shows the most important features.

A box and whisker plot is a graph that presents information from a five-number summary. It's ideal for comparing distributions because the center, spread, and overall range are immediately apparent. In a box and whisker plot: the ends of the box are the upper and lower quartiles, so the box spans the interquartile range, the median is marked by a horizontal line inside the box, and the whiskers are the two lines outside the box that extend to the highest and lowest observations 5 .

Under the analytical charts, we can also see the full list of the names of the courses, where each student has the following data: page view, participation, submissions, on-time/late/missing submissions, and the current score. For example, based on these data, we can easily identify dropout students and give them targeted additional support materials or even consultation times.

\section{Launch open courses (MOOC) in the Canvas framework}

As part of ELTE's e-learning strategy, we are not only launching courses that support formal education, but also open courses both in Hungarian and English for which anyone can register. The first stage of achieving this goal was the „Open Course Designing”6 MOOC course we launched in October 2018, which will be followed by new courses in a wide range of topics in the near future.

\footnotetext{
${ }^{5}$ Statistics: Power from Data! Box and whisker plots; https://www150.statcan.gc.ca/n1/edu/power-pouvoir/ch12/5214889-eng.htm

${ }^{6} \underline{\text { https://mooc.elte.hu/courses/451 }}$
}

Central-European Journal of New Technologies in Research, Education and Practice 
The course was facilitated from October 2018 to early December, with 1096 participants participating in it, and a total of 1552 forum posts were created in the 88 forums.

One of the specialties of our course was that we provided access not only to one course, but we have also created a test course for each participant, who was able to test the possibilities of Canvas LMS with an instructor and prepare for their exam.

The evaluation of the examination task was carried out in the form of self-evaluation and peer review, in which the (public) learning journals led by the participants were given an important role, where they could reflect on what they had learned in each module.

\section{Instructor feedback}

Following the introduction of the Canvas, feedbacks were gathered from the instructors about the experience of using the system [2]. The instructors had a need for the use of template scenes, so when they start a course, they can start with different types of templates. Although this is not directly supported by the system, there is no obstacle to offer sample packages for instructors which can be imported into the system at the beginning of the semester, so they can fill it up with content.

The usefulness of the student view (course view, testing it with a student test user account) has been highlighted by several people, as it is the easiest way to test how the course is presented to the students.

Quizzes and surveys are used by many instructors, but the question of the cloning option is often denounced by many, just like importing a question bank from another system which causes many problems. Several instructors indicated that it is very easy to assign extra time for filling surveys/quizzes for those students who got special educational needs; it is also a very useful feature. It is also easier for many instructors to limit the types of the files uploaded by students to each task, such as when we expect a PDF file, so students cannot upload a file with a DOC extension, which makes the corrections process easier. Some of the instructors would highly appreciate the option of a mark to indicate that the task should be revised, now it is only possible to give notes, instructions, and opinions in a free text block beside the scoring.

Currently, student attendance can be recorded in the same way as the assignments, which according to the instructors should be separated from the assignments.

\section{Conclusion}

We can see that in the Canvas LMS system, there are a number of functions that fit into the modern pedagogical toolkit, the advanced course management, and evaluation solutions can be used in both mixed and online educational forms. However, in order to maximize the use of these opportunities for instructors, it is necessary to initiate methodological training.

The Canvas LMS's functionality can be expanded to include LTI (Learning Tools Interoperability) tools, including gamification, absences management, content sharing, and custom assessment examination functions, in addition to the features described in this article.

Central-European Journal of New Technologies in Research, Education and Practice

Volume 2, Number 1, 2020. 


\section{Bibliography}

1. Canvas Doc Team: Canvas Instructor Guide. 2019.

[on-line] https://community.canvaslms.com/docs/DOC-10460

2. Abonyi-Tóth, Andor; Tóth-Mózer, Szilvia: A Canvas LMS használatának tapasztalatai az ELTE képzéseiben. In: Nádasi, András (szerk.) Agria Media 2017 : „A digitális átállás a tanulást élménnyé teszi” = „Digital transformation as a key to experience - based learning ” Eger, Magyarország : EKE Líceum Kiadó, (2018) pp. 49-57. , 9 p

3. Hambleton, R.K., Swaminathan, H., Algina, J., \& Coulson, D.: Criterion referenced testing and measurement: a review of technical issues and developments. Review of Educational Research, 1978, 48(1), 1-47.

4. Southwestern University: Benefits of Peer Review. [on-line] https://bit.ly/2WiK7ux

5. Linda Crocker: Introduction to Measurement Theory (in Handbook of Complementary Methods in Education Research, Routledge, 2012, 371-384)

The course "Designing Open Courses" was created in the framework of the EFOP-3.4.3-16-2016-00011

\section{Authors}

\section{ABONYI-TÓTH Andor}

Eötvös Loránd University, Faculty of Informatics, Department of Media and Educational Informatics, Budapest, Hungary, e-mail: abonyita@inf.elte.hu

\begin{abstract}
About this document
Published in:

CENTRAL-EUROPEAN JOURNAL OF

NEW TECHNOLOGIES IN RESEARCH, EDUCATION AND PRACTICE
\end{abstract}

Volume 2, Number 1. 2020.

ISSN: 2676-9425 (online)

DOI:

10.36427/CEJNTREP.2.1.419

\section{License}

Copyright (C) ABONYI-TÓTH Andor. 2020.

Licensee CENTRAL-EUROPEAN JOURNAL OF NEW TECHNOLOGIES IN RESEARCH, EDUCATION AND PRACTICE, Hungary. This article is an open access article distributed under the terms and conditions of the Creative Commons Attribution (CC-BY) license.

http://creativecommons.org/licenses/by/4.0/

Central-European Journal of New Technologies in Research, Education and Practice

Volume 2, Number 1, 2020. 